\title{
Parameters of Stromal Activation and Epithelial to Mesenchymal Transition as Predictive Biomarkers for Induction Chemotherapy in Patients With Locally Advanced Oral Cavity and Oropharyngeal Squamous Cell Cancer
}

\author{
Jana Geweiler ${ }^{1} \cdot$ Johanna Inhestern $^{2} \cdot$ Alexander Berndt $^{1} \cdot$ Orlando Guntinas-Lichius $^{2}$ \\ ${ }^{1}$ Institute of Pathology and ${ }^{2}$ Department of Otorhinolaryngology, Jena University Hospital, Jena, Germany
}

Objectives. Induction chemotherapy (IC) is likely to be effective for biologically distinct subgroups of oral cancer and biomarker development may lead to identification of those patients.

Methods. We evaluated immune cell infiltration, stroma formation and structure of the invasive front as well as the immunohistochemical expression of alpha smooth muscle actin (ASMA), CD163, E-cadherin, N-cadherin, and the laminin gamma 2 chain in pretreatment biopsy specimens and surgical resections after IC in 20 patients with locally advanced oral cancer who were treated in a prospective, ongoing, phase II trial on IC using docetaxel, cisplatin, and 5 -fluorouracil (TPF).

Results. Significant negative prognostic factors for incomplete pathological tumor response to IC were alcohol abuse $(P=0.032), \mathrm{cN}+(P=0.042)$, and $<30 \%$ tumor reduction after first cycle of IC $(P=0.034)$. Of the investigated histological parameters and biomarkers only a low membrane-bound expression of E-cadherin showed a trend to be associated with incomplete response to IC $(P=0.061)$. Low expression of ASMA in stromal vessels and a strong tumor invasion front were significantly associated to tumor recurrence $(P=0.024$ and $P=0.004$, respectively). The median follow-up of all patients was 35 months. Alcohol abuse $(P<0.001),<30 \%$ tumor reduction after first cycle of IC $(P=0.005)$, and a strong tumor invasion front $(P=0.019)$ were negative prognostic factors for overall survival.

Conclusion. A strong predictive biomarker among the investigated parameters for benefitting from TPF IC could not be found. The extent of the tumor invasion front was a negative prognostic marker for recurrence and survival in oral cancer treated by TPF IC followed by surgery and postoperative radiochemotherapy.

Keywords. Induction Chemotherapy; Mouth Neoplasms; Docetaxel; Neoplasm Invasiveness; Survival

\section{INTRODUCTION}

As a component of multimodal therapy in locally advanced

- Received November 2, 2015

Revised January 21, 2016

Accepted February 17, 2016

- Corresponding author: Orlando Guntinas-Lichius

Department of Otorhinolaryngology, Jena University Hospital,

Lessingstrasse 2, Jena D-07740, Germany

Tel: +49-3641-935127, Fax: +49-3641-935129

E-mail: orlando.guntinas@med.uni-jena.de head and neck cancer, induction chemotherapy (IC) represents a strategy to reduce tumor burden and target distant metastases prior to definitive treatment [1]. The addition of taxanes to the cisplatin and 5-fluorouracil induction regimen (TPF) has significantly improved outcomes in comparison with cisplatin and 5-fluorouracil (PF) alone [2,3]. However, as a recent phase II trial (DeCIDE) and a phase III trial (PARADIGM) may have been underpowered to show a survival advantage for TPF induction followed by chemoradiotherapy versus chemoradiotherapy alone $[4,5]$, there is an ongoing debate which subset of patients

Copyright () 2016 by Korean Society of Otorhinolaryngology-Head and Neck Surgery.

This is an open-access article distributed under the terms of the Creative Commons Attribution Non-Commercial License (http://creativecommons.org/licenses/by-nc/4.0)

which permits unrestricted non-commercial use, distribution, and reproduction in any medium, provided the original work is properly cited. 
may benefit from TPF [6,7]. Recently, it has been shown that growth differentiation factor 15 (GDF15) expression can be used as a prognostic biomarker for oral squamous cell carcinoma, and as a predictive biomarker for benefitting from TPF IC [8]. Furthermore, patients with low annexin A1 expression or low p53 expression significantly profited more from TPF IC than patients with high expression of the these oncogenic factors $[9,10]$.

However, a lower rate of distant metastatic disease was noted in the above mentioned DeCIDE study, suggesting that patients who are at high risk for metastatic disease may benefit from IC [7]. For epithelial malignancies, the epithelial-mesenchymal transition (EMT) is considered to be the crucial event in the metastatic process [11]. EMT is defined as loss of epithelial morphology and acquisition of migratory mesenchymal features, which allows the tumor cells to pass through the basement membrane and to travel to the site of metastasis formation. EMT is achieved by down-regulation of epithelial cell junction proteins like E-cadherin and for instance by de novo expression of mesenchymal proteins such as vimentin [11,12]. Furthermore, EMT is not only crucial for tumor biological behavior and progression of oral cancer. It seems to be also a cellular strategy for the development of drug resistance [13].

Stromal components, i.e., the microenvironment of the tumor, play a key role in the process of EMT [14]. Tumor-stroma cross talk is evidenced as a precondition for the development of the invasive tumor cell phenotype also in oral squamous cell carcinoma. This is accompanied by a fibroblast to myofibroblast transition also suggested as the main source of the so called carcinoma associated fibroblasts (CAFs). These alpha smooth muscle actin (ASMA) positive CAFs are able to modulate phenotype and signaling pathways of the carcinoma cells towards a more motile/aggressive stage. Indeed it could be shown that the expression level of ASMA is a marker for prognosis in oral squamous cell carcinoma (OSCC) $[15,16]$. Again, with respect to the crucial impact of CAFs on oral carcinoma cell phenotype, they also may play a critical role in modulating therapy sensitivity in head and neck cancer [17].

Up to now, the predictive value of the expression of stromal activation and EMT markers for IC efficacy is not investigated in detail. Hence, the present translational clinical study used a subset of patients of an ongoing prospective clinical phase II trial TISOC-1 (ClinicalTrials.gov; NCT01108042) to evaluate tumor

\section{H I $G$ G H L I I G H T T S}

- The effect of induction chemotherapy on the tumor stroma of oral cancer was analyzed.

- A strong predictive biomarker for benefitting from induction chemotherapy was not found.

- A strong tumor invasion front was a negative prognosticator for recurrence and survival. stroma and EMT predictive biomarkers for better selection of patients for treatment regimens using TPF IC. Standard histology was used (1) to analyze the tumor stroma formation, inflammatory reaction, and mode of invasion. Immunohistochemistry was applied to (2) characterize the stromal activation using the stromal markers ASMA and CD163, and (3) to explore the extend of EMT using the EMT markers E-cadherin, N-cadherin and cytoplasmic laminin gamma 2 prior to IC and after IC.

\section{MATERIALS AND METHODS}

\section{Patients}

This translational study was part of an ongoing prospective multicenter phase I/II clinical trial (TISOC-1; ClinicalTrials.gov; NCT01108042; 72 patients included; last patient in, August 2013; last patient out, December 2015). The first 20 patients treated at the study center at the Jena University Hospital, Jena, took place in this translational study. The per-protocol follow-up of the 50th patient ended in January 2014. Therefore, it was possible to report the outcome of this translational study before the phase II clinical trial is ended. The protocol was approved by the ethics committee for human research at the Medical Faculty, Friedrich-Schiller-University Jena. All patients provided written informed consent before registration. Demographic and medical variables were measured by chart review. TNM staging was performed according to the American Joint Committee on Cancer (AJCC) cancer staging classification (2010). The chart review provided the basis to assess the tumor and treatment characteristics. Alcohol consumption was categorized into $<25 \mathrm{~g} /$ day and $>25 \mathrm{~g} /$ day. Patients were classified as smokers if they smoked cigarettes or quit smoking $\leq 3$ months ago. All other patients were classified as nonsmokers.

\section{Therapy}

TISOC-1 studies the outcome of docetaxel, cisplatin und 5-fluorouracil (TPF) as IC prior to surgery and postoperative radiotherapy or radiochemotherapy in cavity of the mouth and oropharyngeal cancer [18]. Patients received a split-dose regime of TPF $\left(30 \mathrm{mg} / \mathrm{m}^{2}\right.$ docetaxel, $40 \mathrm{mg} / \mathrm{m}^{2}$ cisplatin, and $2,000 \mathrm{mg} / \mathrm{m}^{2}$ 5 -fluorouracil) on two day 1 and 8 per cycle for one or three 3 -week cycles prior to surgery and postoperative radiotherapy or radiochemotherapy. Chemotherapy was applied with usual premedications, appropriate antiemetics and intravenous hydration. Tumor response was evaluated on day 21 using a clinical examination with endoscopy of the primary tumor. Tumor response to chemotherapy was defined by the Response Evaluation Criteria in Solid Tumors (RECIST) criteria and as a reduction of the tumor volume $\geq 30 \%$. All responders received two more cycles of split-TPF, i.e., responders underwent surgery after three cycles and nonresponders after one cycle of CT whereas nonresponders underwent surgery after one cycle of surgery. 
Surgery was performed within 3-5 weeks after chemotherapy. Surgery was performed within the original tumor margins prior to TPF IC. Ipsilateral neck dissection was obligatory. For tumors crossing the midline a contralateral neck dissection was recommended. Start of postoperative radiotherapy was recommended not later than 8 weeks after last surgery. Criteria for high risk patients were: $\mathrm{R} 1$ resection, resection margins $<5 \mathrm{~mm}$, extracapsular spreading, perineural tumor growth, vascular tumor embolus, lymph node metastasis in level IV orV, >2 positive lymph nodes. All other patients were classified as low risk patients. Low risk patients received postoperative radiotherapy (3-D conformal or with intensity modulated radiotherapy). High risk patients received radiochemotherapy with cisplatin $\left(20 \mathrm{mg} / \mathrm{m}^{2}\right)$ five times in week 1 and week 5 of radiotherapy.

\section{Histology and immunohistochemistry}

Pretreatment biopsies and resected surgical samples of the primary tumor were collected, formalin-fixed, and paraffin-embedded. For histology and immunohistochemistry $4 \mu \mathrm{m}$ paraffin sections were used. Standard histopathology was performed with hematoxylin and eosin staining. For immunohistochemistry sections were incubated with the monoclonal antibodies against ASMA (1:600; clone 1A4; DakoCytomation, Hamburg, Germany), E-cadherin (1:500; clone NCH-38; DakoCytomation), Ncadherin (1:100; clone 6G11; DakoCytomation), laminin gamma 2 (1:3,000; clone D4B5; Chemicon/Merck Chemicals $\mathrm{GmbH}$, Schwalbach, Germany), or CD163 (1:500; clone 10D6; Novocastra/Leica Mikrosysteme Vertrieb GmbH, Wetzlar, Germany) for 1 hour at room temperature, respectively. Negative control was performed by using tris-buffered saline (TBS) instead of primary antibodies. For detection of the primary antibodies by means of bright field microscopy, the Dako REAL Detection System and, in case of CD163, the Envision Flex Detection System (both from DakoCytomation) were used as recommended by the manufacturer. All samples were evaluated in the light microscope (Axioscop-2; Zeiss; Jena, Germany) independently by two investigators (JG and $\mathrm{AB}$ ), and then jointly for consensus. The investigators were blinded to the clinicopathologic data at the time of the evaluation. Evaluation of the tumor stroma, inflammatory reaction, and mode of invasion was performed using the hematoxylin and eosin stained slides according to $[19,20]$. Both, histological parameters as well as immunohistochemical detection levels of the positivity of the different antibodies were semiquantitatively assessed using a $0-3$ scoring system (Supplementary Table 1). For the statistical evaluation, the scores 0 and 1 were summarized as "no/low" and the scores 2 and 3 as "high."

\section{Statistical analysis}

Statistical analyses were performed using IBM SPSS ver. 21.0 (IBM Co., Armonk, NY, USA). To compare patient and tumor characteristics to the rate of pathological complete response to
IC, recurrence, and death, Pearson chi-square test was used. Therefore, if necessary, all data of these parameters were dichotomized to categorical data using median values as separators. Overall survival was calculated by the Kaplan-Meier method and differences of survival were compared by the log-rank test.

Table 1. Patients' and tumor and therapy characteristics $(n=20)$

\begin{tabular}{|c|c|c|}
\hline Measure & $\begin{array}{l}\text { Absolute no. of } \\
\text { patients or } \\
\text { mean } \pm S D\end{array}$ & $\begin{array}{l}\text { Relative no. of } \\
\text { patients (\%) or } \\
\text { median (range) }\end{array}$ \\
\hline \multicolumn{3}{|l|}{ Sex } \\
\hline Male & 15 & 75 \\
\hline Female & 5 & 25 \\
\hline \multicolumn{3}{|l|}{ Smoker } \\
\hline No & 5 & 25 \\
\hline Yes & 15 & 75 \\
\hline \multicolumn{3}{|l|}{ Chronic alcohol abuse } \\
\hline No & 14 & 70 \\
\hline Yes & 6 & 30 \\
\hline \multicolumn{3}{|l|}{ Localization of the tumor } \\
\hline Cavity of the mouth & 8 & 40 \\
\hline Oropharynx & 12 & 60 \\
\hline \multicolumn{3}{|l|}{ cT classification } \\
\hline cT2 & 9 & 45 \\
\hline сT3 & 5 & 25 \\
\hline cT4 & 6 & 30 \\
\hline \multicolumn{3}{|l|}{ cN classification } \\
\hline cNO & 2 & 10 \\
\hline $\mathrm{cN} 1$ & 1 & 5 \\
\hline $\mathrm{cN} 2$ & 16 & 80 \\
\hline $\mathrm{cN3}$ & 1 & 5 \\
\hline \multicolumn{3}{|l|}{ cStage } \\
\hline III & 2 & 20 \\
\hline IV & 18 & 80 \\
\hline \multicolumn{3}{|l|}{ Therapy arm } \\
\hline A (1 cycle of IC) & 8 & 40 \\
\hline B (3 cycles of IC) & 12 & 60 \\
\hline \multicolumn{3}{|l|}{ Tumor reduction $>30 \%$ first cycle IC } \\
\hline Yes & 12 & 60 \\
\hline No & 6 & 30 \\
\hline IC stopped because of toxicity & 2 & 10 \\
\hline \multicolumn{3}{|l|}{ Therapy } \\
\hline $\mathrm{IC}+$ surgery+RT & 11 & 55 \\
\hline $\mathrm{IC}+$ surgery+RCT & 5 & 25 \\
\hline IC+surgery & 1 & 5 \\
\hline IC+surgery+RIT & 3 & 15 \\
\hline \multicolumn{3}{|l|}{ Recurrence } \\
\hline No & 6 & 30 \\
\hline Yes & 14 & 70 \\
\hline \multicolumn{3}{|l|}{ Death } \\
\hline No & 12 & 60 \\
\hline Yes & 8 & 40 \\
\hline Age (yr) & $57.1 \pm 8.6$ & $56(44-73)$ \\
\hline Body mass index $\left(\mathrm{kg} / \mathrm{m}^{2}\right)$ & $26.5 \pm 5.8$ & $27(17-37)$ \\
\hline Follow-up (mo) & $33.7 \pm 18.7$ & $35(8-60)$ \\
\hline Follow-up of patients alive (mo) & $40.6 \pm 17.6$ & $49(9-60)$ \\
\hline
\end{tabular}

SD, standard deviation; IC, induction chemotherapy; RT, radiotherapy; $\mathrm{RCT}$, radiochemotherapy; RIT, radioimmunotherapy with cetuximab. 

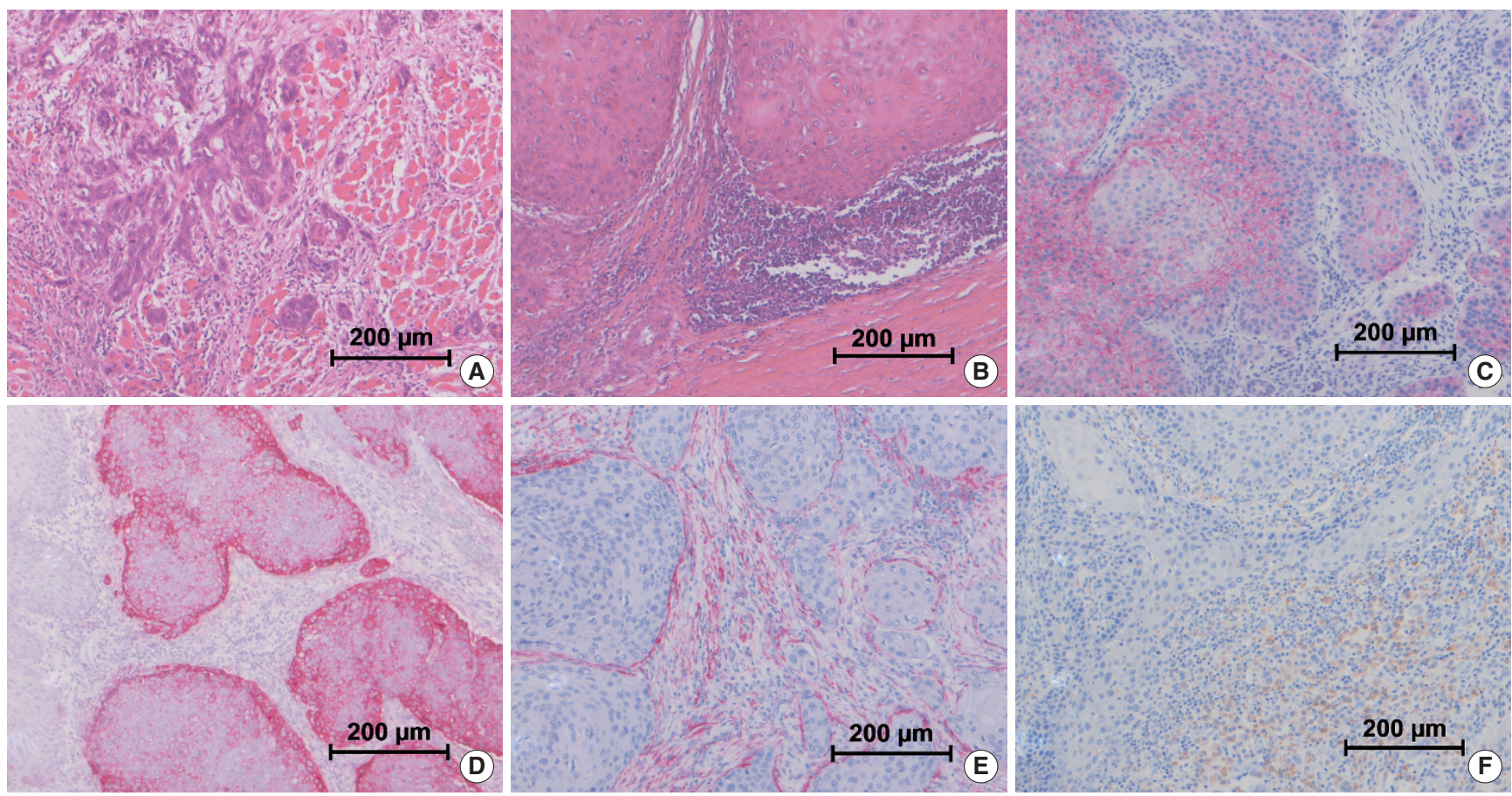

Fig. 1. Histological and immunohistological examples of tumor stroma and epithelial-mesenchymal transition activation in oral cancer prior to induction chemotherapy. (A) H\&E, case 11; mode of invasion, score 3 (detached island/disseminated); Inflammation, score 2 (moderate). (B) $\mathrm{H} \& \mathrm{E}$, case 3; mode of invasion, score 1 (pushing borders); inflammation, score 2-3 (moderate - distinct inflammatory reaction). (C) E-cadherin immunohistochemistry $(\mathrm{IH}$ ), case 21; membranous positivity, score 3 (positive $>30 \%$ tumor area)/red staining. (D) Laminin gamma 2 chain $I H$, case 20; cytoplasmic positivity, score 3 (tumor cells more or less all positive)/red staining. (E) Alpha smooth muscle actin IH, case 3; stromal positivity, score 2-3 (distinct stroma positivity, note the accentuation of the tumor borders)/red staining. (F) CD163 IH, case 3; CD163 positivity, score 2 (many positive cells detectable)/brown staining.

Due to the small sample size, a multivariate analysis was not appropriate. For all statistical tests, significance was two-sided and set to $P<0.05$.

\section{RESULTS}

\section{Subjects}

Details on the patients' characteristics are presented in Table 1. Two thirds of the patients were male and smokers. Median age was 56 years. One third was alcohol dependent and most patients had stage IV tumors. IC was stopped after the first cycle because of insufficient response $<30 \%$ clinical tumor reduction in six patients $(30 \%)$ and because of toxicity on two patients $(10 \%)$. All other 12 patients $(60 \%)$ received three cycles of IC.

\section{Tumor stroma and EMT before and after induction chemo- therapy}

An overview of the histological and immunohistological results on the tumor and tumor stroma characteristics prior to treatment is shown in Supplementary Table 2. Histological and immunohistochemical examples of the tumor stroma and EMT activation are given in Fig. 1. The majority of the tumors showed a high laminin gamma 2 expression, no/low ASMA expression in the stroma but high AMSA expression in the stromal vessels, no/low CD163 expression, and no/low membrane-bound and cytoplasmatic E-cadherin expression. $\mathrm{N}$-cadherin expression was absent or low in all patients. Stroma formation was strong in one thirds of patients. Stromal inflammation was higher in about half of patients, whereas the invasion front structure was "low" (pushing borders) in nearly all patients.

The results of the examination of the surgical specimen after IC and curative surgery are summarized in Supplementary Table 3. IC led to downstaging of the primary tumor in most cases but not of the lymph node metastases. A complete pathological response was seen in seven patients (35\%). Laminin gamma 2 expression decreased in half of the patients, whereas E-Cadherin expression was unchanged in more than half of the patients. Ncadherin expression was predominantly unchanged after IC. Stroma formation, inflammation and mode of invasion were unchanged in most of the patients with residual tumor after IC.

\section{Tumor stroma and EMT as prognostic biomarkers}

The negative prognostic role of all relevant parameters concerning no pathological complete response, tumor recurrence and death of the patients is presented in Table 2. Significant negative 
Table 2. Prognostic factor for no pathological complete remission, tumor recurrence, or death

\begin{tabular}{|c|c|c|c|}
\hline Measure $^{\text {a) }}$ & No $\mathrm{pCR}$ & Recurrence & Death \\
\hline Sex (male) & 0.176 & 0.573 & 1.000 \\
\hline Age (<median $56 \mathrm{yr})$ & 0.639 & 1.000 & 0.361 \\
\hline Smoker (yes) & 0.787 & 0.573 & 0.292 \\
\hline Alcohol abuse (yes) & $0.032^{*}$ & 0.831 & $0.010^{*}$ \\
\hline Body mass index (<median 27) & 0.160 & 1.000 & 0.361 \\
\hline Localization (cavity of mouth) & 0.085 & 0.550 & 0.456 \\
\hline cT (T2 vs. T3-4) & 0.888 & 0.492 & 0.714 \\
\hline $\mathrm{cN}(\mathrm{N}+)$ & $0.042^{*}$ & 0.515 & 0.224 \\
\hline Therapy arm (arm A) & 0.085 & 0.690 & 0.094 \\
\hline Tumor reduction first cycle IC (<30\%) & $0.034^{*}$ & 1.000 & $0.019^{*}$ \\
\hline Grading (G3 vs. G1-2) & 0.919 & 0.394 & 0.690 \\
\hline HPV (negative) & 0.848 & 0.690 & 0.852 \\
\hline $\mathrm{HPV}+$ and nonsmoker (no) & 0.639 & 0.515 & 0.224 \\
\hline Laminin gamma 2 (low) & 0.901 & 0.622 & 0.349 \\
\hline Alpha smooth muscle actin stroma (low) & 0.793 & 0.311 & 0.394 \\
\hline $\begin{array}{l}\text { Alpha smooth muscle actin in vessels } \\
\text { (low) }\end{array}$ & 0.888 & $0.024^{*}$ & 0.199 \\
\hline CD163 (high) & 0.938 & 0.659 & 0.938 \\
\hline E-cadherin/membrane-bound (low) & 0.061 & 0.143 & 0.494 \\
\hline E-cadherin/cytoplasmatic (low) & 0.589 & 0.260 & 0.444 \\
\hline N-cadherin & NA & NA & NA \\
\hline Stroma formation (high) & 0.058 & 0.573 & 0.292 \\
\hline Inflammation (high) & 0.423 & 0.492 & 0.714 \\
\hline Invasion front (high) & 0.948 & $0.004^{*}$ & $0.021^{*}$ \\
\hline $\begin{array}{l}\text { Change }^{b} \text { laminin gamma } 2 \\
\text { (not lower) }\end{array}$ & 0.627 & 0.682 & 0.115 \\
\hline $\begin{array}{l}\text { Change alpha smooth muscle actin } \\
\text { stroma (not lower) }\end{array}$ & 0.643 & 0.404 & 0.266 \\
\hline $\begin{array}{l}\text { Change E-cadherin/membrane } \\
\text { (not lower) }\end{array}$ & 0.061 & 0.143 & 0.494 \\
\hline $\begin{array}{l}\text { Change E-cadherin/cytoplasmatic } \\
\text { (not lower) }\end{array}$ & 0.589 & 0.260 & 0.444 \\
\hline Change $\mathrm{N}$-cadherin & NA & NA & NA \\
\hline Change stroma formation (not lower) & NA & 0.197 & 0.389 \\
\hline Change inflammation (not lower) & NA & 0.260 & 0.778 \\
\hline Change invasion front (not lower) & NA & 0.197 & 0.389 \\
\hline
\end{tabular}

$\mathrm{pCR}$, pathological complete response; HPV, human papilloma virus; NA, not applied.

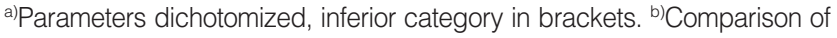
pre-induction chemotherapy versus post-induction chemotherapy. ${ }^{*} P<0.05$. prognostic factors for incomplete tumor response to IC were alcohol abuse $(P=0.032), \mathrm{cN}+(P=0.042)$, and no significant $(<30 \%)$ tumor reduction after first cycle of IC $(P=0.034)$. Of the investigated biomarkers only a low membrane-bound expression of E-cadherin showed a trend to be associated with incomplete response to IC $(P=0.061)$. Low expression of ASMA in the stromal vessels and a "high" tumor invasion front (disseminated invasion pattern) were significantly associated to tumor recurrence $(P=0.024$ and $P=0.004$, respectively). Alcohol abuse $(P=0.010)$, no relevant tumor reduction after first cycle of IC $(P=0.019)$, and again a strong tumor invasion front $(P=$ 0.021 ) were correlated to higher probability of patient's death after cancer treatment. A subanalysis of only the patients receiving 3 cycles of IC confirmed that a strong tumor invasion front was correlated to higher risk of recurrence and death $(P=0.005$ and $P=0.001$, respectively) (Supplementary Table 4). Furthermore, a low expression of membrane-bound E-cadherin was related in this subset of patients to higher risk of incomplete response to IC $(P=0.046)$.

The median follow-up of all patients and patients alive was 35 months and 49 months, respectively. The overall survival analyses are shown in Supplementary Table 5. In correspondence to the results presented above, alcohol abuse $(P<0.001)$, no relevant tumor reduction after first cycle of IC $(P=0.005)$, and a "high" tumor invasion front $(P=0.019)$ were negative prognostic factors for overall survival (Fig. 2).

\section{DISCUSSION}

To our knowledge, the presented analysis is a small but first and prospective evaluation of the effect of the tumor stroma and EMT on IC in patients with cancer of the oral cavity and the oropharynx. In most therapy strategies and studies using IC, IC with TPF is normally followed by radiotherapy or radiochemotherapy, i.e., surgical specimens after IC are not available [2]. That means that in such studies prognostic biomarkers, for instance, for overall survival in a therapy setting using TPF IC can be studied but not the predictive value of IC on the pathological
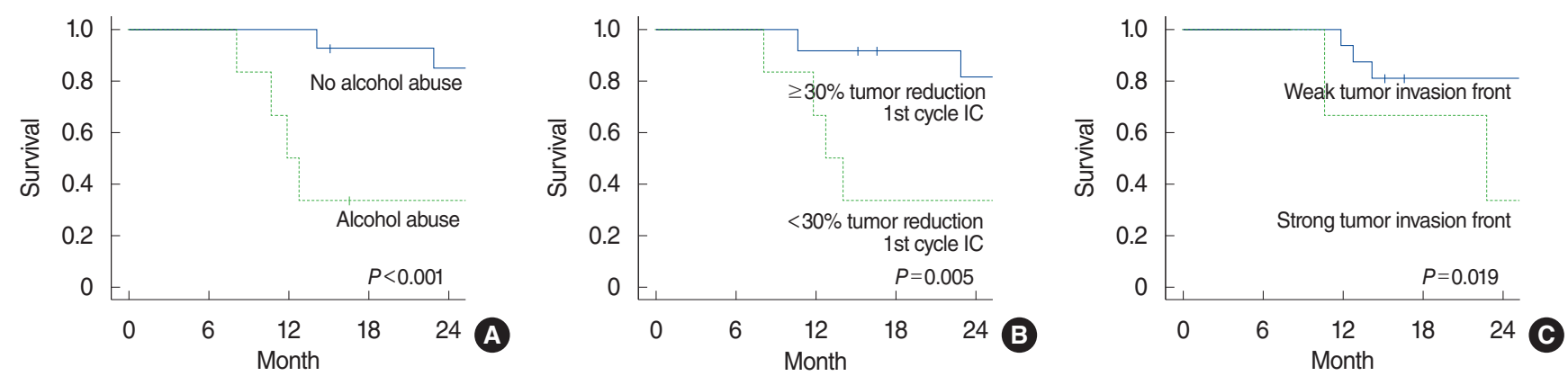

Fig. 2. Kaplan-Meier curves on overall survival, related to alcohol abuse (A), response to first cycle of induction chemotherapy (B), and structure of the tumor invasion front (C). Results of the log rank tests are shown. 
tumor response. For instance, it was shown that the expression of the biomarkers beta tubulin II, glutathione S-transferase, p53, or B-cell lymphoma 2 in the head and neck tumor treated with TPF IC is associated with worse outcome [21,22]. High annexin A1 expression is linked to worse survival after TPF IC in oral cancer [9]. This may be due to its role in plasma membrane repair after membrane injury which is caused by mechanical stress during cell invasion and metastasis [23]. However, all these markers are not directly linked to the tumor stroma or EMT.

Beside the present study, there is only one other study published which had access to a prospective clinical trial on TPF IC following by surgery, i.e., access to specimens after IC [8]. This Chinese study showed that GDF15 overexpression in the tumors was negative predictive marker for benefitting from TPF IC. The tumor stroma was not analyzed [8]. With respect to tumor stroma and EMT, we found that the majority of the patients showed a high cytoplasmic laminin gamma 2 chain expression in tumor cells prior to treatment. In line with that, it is well known that laminin gamma 2 as an EMT marker is correlated with the invasiveness of the tumor. The laminin gamma 2 expression is also correlated to the ASMA expression speaking well for the important role of stromal myofibroblast transdifferentiation for cancer cell phenotype transition and vice versa $[24,25]$. In the present study only a quarter of the patients showed a high ASMA expression in the stroma but the majority showed a high ASMA expression in the stromal vessels. Anyhow, in accordance to the literature the degree of stromal ASMA was significantly correlated to the laminin gamma 2 expression (data not shown) [25]. Stromal ASMA expression as a sign of CAF development is an indirect marker of the EMT activity of the tumor and therefore a known risk factor for metastasis formation [14,17]. In the present study, stromal expression of CD163 was low in most cases. CD163 is a marker of tumor stroma-associated M2 macrophages. Increased expression of CD163 was significantly associated with a poor overall survival in several cancers but only one study has confirmed that for oral cancer [26]. We could not confirm this role for CD163 in the present study although at least about half of the patients in the present study showed tumor stroma with strong inflammatory reaction. E-cadherin and $\mathrm{N}$-cadherin, opposite acting EMT biomarkers, predominately showed low expression profiles in untreated tumors. Loss of E-cadherin, i.e., low E-cadherin expression and less control over local cell adhesion in the tumor stroma is correlated to worse outcome [11,27]. Inversely high $\mathrm{N}$-cadherin expression is correlated to worse outcome, because it increases extracellular matrix-associated proteolytic activity to facilitate invasiveness in oral tumor development [28]. Overall, most of the observed EMT and stromal marker profiles correlated to data from the literature. Also vascular ASMA showed a significant negative correlation to recurrence in the present investigation. Low vessel associated ASMA positivity may reflect a higher percentage of immature vessels and therefore a higher angiogenetic potential of the tumor. Although critically discussed, high microvessel density was shown to be a risk factor for recurrence in OSCC $[29,30]$. Nevertheless, classical histological evaluation of the tumor invasion front into the tumor stroma was highly predictive for worse survival as it has also been shown in other recent studies [31,32]. We therefore hypothesize that the influence of IC on the tumor stroma might be a reason why TPF IC seems to reduce the cumulative incidence of distant metastasis [5].

Concerning the prediction of complete pathological response to TPF IC, no significant stromal marker could be detected in the present study. When considering all patients, only low E-cadherin expression showed a statistical trend to be correlated to incomplete pathological response. In the subset of patients receiving all three cycles of IC, low E-cadherin expression was significantly associated to higher probability of incomplete pathological response. Low E-cadherin may represent an ongoing mesenchymal phenotype transition toward a more therapy resistant phenotype. In the only other study with surgical resection specimens available after TPF IC (there is even no other study published analyzing surgical specimens after any kind of IC in oral cancer), the authors did not performed any analysis related to the pathological tumor response [8]. Interestingly, the individual stromal biomarker expression profiles did not change in the majority of the patients. This might explain why alteration of the stroma after TPF IC did not have any predictive value on pathological tumor response, recurrence or death of the patients.

It is important to address the limitations of the present study. Although it is the largest study published so far reporting on tumor stroma reaction prior to IC compared to after IC, the sample was small with 20 patients. This might explain why some well-known negative prognostic factors for overall survival like $\mathrm{T}$ and $\mathrm{N}$ classification did not reach statistical significance although the related Kaplan-Meier curves take a completely different and separated course. Against this background the fact that a disseminated mode of invasion was shown to be a significant negative risk factor for overall survival is all the more important. Nevertheless, the sample size was too small to allow a meaningful multivariate analysis. The pretreatment histological and immunohistological assessment of the tumors was based on several representative biopsies from different subsites of the tumor but not based on serial sections from the complete specimen as it was possible for the postoperative assessment. Therefore, we finally cannot rule out that some variability of the pretreatment results is related to a biopsy selection bias.

It seems to be worthwhile to extent the research on the relation between IC and tumor stroma and EMT in head and neck cancer patients on larger study samples. Furthermore, as TPF IC seems to be most advantage in nonoropharyngeal sites, we would like to explore the role of stromal biomarkers in nonoropharyngeal tumors, for instance in laryngeal or hypopharyngeal cancer [4]. Finally, as IC with TPF incorporating cetuximab ap- 
pears to yield a greater response than TPF, it would be interest to investigate stromal biomarkers after IC strategies including cetuximab [33].

\section{CONFLICT OF INTEREST}

No potential conflict of interest relevant to this article was reported.

\section{REFERENCES}

1. Argiris A. Current status and future directions in induction chemotherapy for head and neck cancer. Crit Rev Oncol Hematol. 2013 Oct;88(1):57-74.

2. Posner MR, Hershock DM, Blajman CR, Mickiewicz E, Winquist E, Gorbounova V, et al. Cisplatin and fluorouracil alone or with docetaxel in head and neck cancer. N Engl J Med. 2007 Oct;357 (17):170515.

3. Vermorken JB, Remenar E, van Herpen C, GorliaT, Mesia R, Degardin $\mathrm{M}$, et al. Cisplatin, fluorouracil, and docetaxel in unresectable head and neck cancer. N Engl J Med. 2007 Oct;357(17):1695-704.

4. Haddad R, O'Neill A, Rabinowits G, Tishler R, Khuri F, Adkins D, et al. Induction chemotherapy followed by concurrent chemoradiotherapy (sequential chemoradiotherapy) versus concurrent chemoradiotherapy alone in locally advanced head and neck cancer (PARADIGM): a randomised phase 3 trial. Lancet Oncol. 2013 Mar; 14 (3):257-64.

5. Cohen EE, Karrison TG, Kocherginsky M, Mueller J, Egan R, Huang $\mathrm{CH}$, et al. Phase III randomized trial of induction chemotherapy in patients with N2 or N3 locally advanced head and neck cancer. J Clin Oncol. 2014 Sep;32(25):2735-43.

6. Benasso M. Induction chemotherapy for squamous cell head and neck cancer: a neverending story? Oral Oncol. 2013 Aug;49(8):74752.

7. Hanna GJ, Haddad RI, Lorch JH. Induction chemotherapy for locoregionally advanced head and neck cancer: past, present, future? Oncologist. 2013;18(3):288-93.

8. Yang CZ, Ma J, Zhu DW, Liu Y, Montgomery B, Wang LZ, et al. GDF15 is a potential predictive biomarker for TPF induction chemotherapy and promotes tumorigenesis and progression in oral squamous cell carcinoma. Ann Oncol. 2014 Jun;25(6):1215-22.

9. Zhu DW, Liu Y, Yang X, Yang CZ, Ma J, Yang X, et al. Low Annexin A1 expression predicts benefit from induction chemotherapy in oral cancer patients with moderate or poor pathologic differentiation grade. BMC Cancer. 2013 Jun;13:301.

10. Kim MJ, Ki MS, Kim K, Shim HJ, Hwang JE, Bae WK, et al. Different protein expression associated with chemotherapy response in oropharyngeal cancer according to HPV status. BMC Cancer. 2014 Nov;14:824.

11. Pectasides E, Rampias T, Sasaki C, Perisanidis C, Kouloulias V, Burtness B, et al. Markers of epithelial to mesenchymal transition in association with survival in head and neck squamous cell carcinoma (HNSCC). PLoS One. 2014 Apr;9(4):e94273.

12. Smith A, Teknos TN, Pan Q. Epithelial to mesenchymal transition in head and neck squamous cell carcinoma. Oral Oncol. 2013 Apr; 49(4):287-92.

13. Vig N, Mackenzie IC, Biddle A. Phenotypic plasticity and epithelialto-mesenchymal transition in the behaviour and therapeutic response of oral squamous cell carcinoma. J Oral Pathol Med. 2015
Oct;44(9):649-55.

14. Rasanen K, Vaheri A. Activation of fibroblasts in cancer stroma. Exp Cell Res. 2010 Oct;316(17):2713-22.

15. Fujii N, Shomori K, ShiomiT, Nakabayashi M,Takeda C, Ryoke K, et al. Cancer-associated fibroblasts and CD163-positive macrophages in oral squamous cell carcinoma: their clinicopathological and prognostic significance. J Oral Pathol Med. 2012 Jul;41(6):444-51.

16. Ding L, Zhang Z, Shang D, Cheng J, Yuan H, Wu Y, et al. $\alpha$-Smooth muscle actin-positive myofibroblasts, in association with epithelialmesenchymal transition and lymphogenesis, is a critical prognostic parameter in patients with oral tongue squamous cell carcinoma. J Oral Pathol Med. 2014 May;43(5):335-43.

17. Zhou B, Chen WL, Wang YY, Lin ZY, Zhang DM, Fan S, et al. A role for cancer-associated fibroblasts in inducing the epithelial-to-mesenchymal transition in human tongue squamous cell carcinoma. J Oral Pathol Med. 2014 Sep;43(8):585-92.

18. Oertel K, Spiegel K, Schmalenberg H, Dietz A, Maschmeyer G, KuhntT, et al. Phase I trial of split-dose induction docetaxel, cisplatin, and 5-fluorouracil (TPF) chemotherapy followed by curative surgery combined with postoperative radiotherapy in patients with locally advanced oral and oropharyngeal squamous cell cancer (TISOC-1). BMC Cancer. 2012 Oct;12:483.

19. Anneroth G, Batsakis J, Luna M. Review of the literature and a recommended system of malignancy grading in oral squamous cell carcinomas. Scand J Dent Res. 1987 Jun;95(3):229-49.

20. Bryne M, Koppang HS, Lilleng R, Stene T, Bang G, Dabelsteen E. New malignancy grading is a better prognostic indicator than Broders' grading in oral squamous cell carcinomas. J Oral Pathol Med. 1989 Sep;18(8):432-7.

21. Cullen KJ, Schumaker L, Nikitakis N, Goloubeva O, Tan M, Sarlis $\mathrm{NJ}$, et al. beta-Tubulin-II expression strongly predicts outcome in patients receiving induction chemotherapy for locally advanced squamous carcinoma of the head and neck: a companion analysis of the TAX 324 trial. J Clin Oncol. 2009 Dec;27(36):6222-8.

22. WuY, Posner MR, Schumaker LM, Nikitakis N, Goloubeva O,Tan M, et al. Novel biomarker panel predicts prognosis in human papillomavirus-negative oropharyngeal cancer: an analysis of the TAX 324 trial. Cancer. 2012 Apr;118(7):1811-7.

23. Jaiswal JK, Nylandsted J. S100 and annexin proteins identify cell membrane damage as the Achilles heel of metastatic cancer cells. Cell Cycle. 2015;14(4):502-9.

24. Franz M, Richter P, Geyer C, Hansen T, Acuna LD, Hyckel P, et al. Mesenchymal cells contribute to the synthesis and deposition of the laminin-5 gamma2 chain in the invasive front of oral squamous cell carcinoma. J Mol Histol. 2007 Jun;38(3):183-90.

25. Franz M, Wolheim A, Richter P, Umbreit C, Dahse R, Driemel O, et al. Stromal laminin chain distribution in normal, hyperplastic and malignant oral mucosa: relation to myofibroblast occurrence and vessel formation. J Oral Pathol Med. 2010 Apr;39(4):290-8.

26. He KF, Zhang L, Huang CF, Ma SR, Wang YF, Wang WM, et al. CD163+ tumor-associated macrophages correlated with poor prognosis and cancer stem cells in oral squamous cell carcinoma. Biomed Res Int. 2014;2014:838632.

27. Hanemann JA, Oliveira DT, Nonogaki S, Nishimoto IN, de Carli ML, Landman G, et al. Expression of E-cadherin and $\beta$-catenin in basaloid and conventional squamous cell carcinoma of the oral cavity: are potential prognostic markers? BMC Cancer. 2014 Jun;14: 395.

28. Walker A, Frei R, Lawson KR. The cytoplasmic domain of N-cadherin modulates MMP-9 induction in oral squamous carcinoma cells. Int J Oncol. 2014 Oct;45(4):1699-706.

29. Martone T, Rosso P, Albera R, Migliaretti G, Fraire F, Pignataro L, et al. Prognostic relevance of CD105+ microvessel density in HNSCC patient outcome. Oral Oncol. 2005 Feb;41(2):147-55. 
30. Marioni G, Staffieri A, Fasanaro E, Stramare R, Giacomelli L, Bernardi E, et al. The role of angiogenin in pT1-T2 tongue carcinoma neo-angiogenesis and cell proliferation: an exploratory study. J Oral Pathol Med. 2013 Sep;42(8):606-11.

31. Almangush A, Bello IO, Keski-Santti H, Makinen LK, Kauppila JH, Pukkila M, et al. Depth of invasion, tumor budding, and worst pattern of invasion: prognostic indicators in early-stage oral tongue cancer. Head Neck. 2014 Jun;36(6):811-8.
32. Szybiak B, Korski K, GolusinskiW. Role of extended histological examination in the assessment of local recurrence of the oral cancer. Otolaryngol Pol. 2015;69(1):17-21.

33. Kies MS, Holsinger FC, Lee JJ, William WN Jr, Glisson BS, Lin HY, et al. Induction chemotherapy and cetuximab for locally advanced squamous cell carcinoma of the head and neck: results from a phase II prospective trial. J Clin Oncol. 2010 Jan;28(1):8-14. 
Geweiler J et al. Stromal Biomarkers for Induction Chemotherapy in Oral Cancer

Supplementary Table 1. Scoring system for semiquantitative assessment of the investigated parameters

\begin{tabular}{|c|c|c|c|c|}
\hline \multirow{2}{*}{ Parameter } & \multicolumn{4}{|c|}{ Score } \\
\hline & 0 & 1 & 2 & 3 \\
\hline Desmoplastic stroma reaction & None & Low & Moderate & Stroma area $>50 \%$ of the tumor area \\
\hline Inflammatory reaction & None & Few inflammatory cells & Moderate & Distinct inflammatory reaction \\
\hline Predominant mode of invasion & NA & Pushing borders & Solid cords & Detached islands/dissemination \\
\hline Stromal ASMA & No staining & Focal positivity & $\begin{array}{l}\text { Partial positivity and/or positivity of the } \\
\text { invasive borders }\end{array}$ & Stroma more or less complete positive \\
\hline Vascular ASMA & No staining & Few positive vessels & Partial positivity of vessels & Vessels more or less all positive \\
\hline $\begin{array}{l}\text { E-cadherin (cytoplasmic/ } \\
\text { membranous) }\end{array}$ & No staining & $\begin{array}{l}\text { Few areas and/ } \\
\text { or low staining intensity }\end{array}$ & $\begin{array}{l}\text { Partial positivity }<30 \% \text { of tumor area, } \\
\text { moderate staining intensity }\end{array}$ & Positivity $>30 \%$ of tumor area \\
\hline $\mathrm{N}$-cadherin & No staining & - & - & Staining detectable \\
\hline $\begin{array}{l}\text { Laminin gamma } 2 \text { chain } \\
\text { (stromal/cytoplasmic) }\end{array}$ & No staining & Focal positivity & $\begin{array}{l}\text { Partial positivity and/or positivity of the } \\
\text { invasive borders }\end{array}$ & Tumor cells more or less all positive \\
\hline CD163 & No staining & Few positive cells & Many positive cells & NA \\
\hline
\end{tabular}

ASMA, alpha smooth muscle actin; NA, not applied. 


\section{Clinical and Experimental Otorhinolaryngology}

Supplementary Table 2. Pre-treatment histopathology and immunohistochemistry results $(n=20)$

\begin{tabular}{|c|c|c|}
\hline Measure & $\begin{array}{c}\text { Absolute no. } \\
\text { of patients }\end{array}$ & $\begin{array}{l}\text { Relative no. } \\
\text { of patients (\%) }\end{array}$ \\
\hline \multicolumn{3}{|l|}{ Grading } \\
\hline G1 & 2 & 10 \\
\hline G2 & 12 & 60 \\
\hline G3 & 16 & 30 \\
\hline \multicolumn{3}{|l|}{ HPV } \\
\hline Negative & 12 & 60 \\
\hline Positive & 8 & 40 \\
\hline Thereof nonsmoker & 2 & 10 \\
\hline \multicolumn{3}{|l|}{ Laminin gamma 2} \\
\hline No/low expression & 6 & 30 \\
\hline High expression & 11 & 55 \\
\hline Unknown & 3 & 15 \\
\hline \multicolumn{3}{|c|}{ Alpha smooth muscle actin stroma } \\
\hline No/low expression & 12 & 60 \\
\hline High expression & 5 & 25 \\
\hline Unknown & 3 & 15 \\
\hline \multicolumn{3}{|c|}{ Alpha smooth muscle actin in vessels } \\
\hline No/low expression & 9 & 45 \\
\hline High expression & 11 & 55 \\
\hline \multicolumn{3}{|l|}{ CD163 } \\
\hline No/low expression & 14 & 70 \\
\hline High expression & 3 & 15 \\
\hline Unknown & 3 & 15 \\
\hline \multicolumn{3}{|c|}{ E-cadherin/membrane-bound } \\
\hline No/low expression & 16 & 80 \\
\hline High expression & 4 & 20 \\
\hline \multicolumn{3}{|c|}{ E-cadherin/cytoplasmatic } \\
\hline No/low expression & 13 & 65 \\
\hline High expression & 7 & 35 \\
\hline \multicolumn{3}{|l|}{ N-cadherin } \\
\hline No/low expression & 17 & 85 \\
\hline High expression & 0 & 0 \\
\hline Unknown & 3 & 15 \\
\hline \multicolumn{3}{|l|}{ Stroma formation } \\
\hline Low & 15 & 75 \\
\hline High & 5 & 25 \\
\hline \multicolumn{3}{|l|}{ Inflammation } \\
\hline Low & 9 & 45 \\
\hline High & 11 & 55 \\
\hline \multicolumn{3}{|l|}{ Invasion front } \\
\hline Low & 17 & 85 \\
\hline High & 3 & 15 \\
\hline
\end{tabular}

HPV, human papilloma virus. 
Supplementary Table 3. Histopathology and immunohistochemistry after induction chemotherapy and surgery $(n=20)$

\begin{tabular}{|c|c|c|c|c|c|}
\hline Measure & $\begin{array}{c}\text { Absolute } \\
\text { no. }\end{array}$ & $\begin{array}{c}\text { Relative } \\
\text { no. }(\%)\end{array}$ & Measure & $\begin{array}{c}\text { Absolute } \\
\text { no. }\end{array}$ & $\begin{array}{l}\text { Relative } \\
\text { no. (\%) }\end{array}$ \\
\hline ypT classification & & & No/low & 9 & 50 \\
\hline урт0 & 8 & 40 & High & 10 & 50 \\
\hline ypT1 & 7 & 35 & yp Inflammation & & \\
\hline урT2 & 2 & 10 & No/low & 6 & 30 \\
\hline урT3 & 2 & 10 & High & 4 & 20 \\
\hline ypT4 & 1 & 5 & Unknown & 10 & 50 \\
\hline ypN classification & & & yp Invasion front & & \\
\hline ypNO & 9 & 45 & No/low & 7 & 35 \\
\hline ypN1 & 2 & 10 & High & 3 & 15 \\
\hline ypN2 & 9 & 45 & Unknown & 10 & 50 \\
\hline $\mathrm{cT} \rightarrow \mathrm{ypT}$ downstaged & & & Unknown & 3 & 15 \\
\hline Yes & 17 & 85 & Change $^{a)}$ of grading & & \\
\hline No & 3 & 15 & Unchanged & 1 & 5 \\
\hline $\mathrm{cN} \rightarrow \mathrm{ypN}$ downstaged & & & Decrease & 6 & 30 \\
\hline Yes & 8 & 40 & Increase & 4 & 20 \\
\hline No & 12 & 60 & Unknown & 1 & 5 \\
\hline Pathological response & & & Not applicable in ypT0 & 8 & 40 \\
\hline Complete response & 7 & 35 & Change $^{\text {a) }}$ of laminin gamma 2 expression & & \\
\hline Partial response & 10 & 50 & Unchanged & 7 & 35 \\
\hline Stable disease & 3 & 15 & Decrease & 10 & 50 \\
\hline yp Grading & & & Unknown & 3 & 15 \\
\hline G1 & 2 & 10 & Change $^{\text {a) }}$ of alpha smooth muscle actin stroma & & \\
\hline G2 & 3 & 15 & expression & & \\
\hline G3 & 6 & 30 & Unchanged & 10 & 50 \\
\hline Unknown & 1 & 5 & Decrease & 2 & 10 \\
\hline Not applicable in ypT0 & 8 & 40 & Increase & 5 & 25 \\
\hline yp L & & & Unknown & 3 & 15 \\
\hline Positive & 7 & 35 & Change $^{a)}$ of E-cadherin/membrane-bound & & \\
\hline Negative & 8 & 40 & expression & & \\
\hline Unknown & 5 & 25 & Unchanged & 13 & 65 \\
\hline yp V & & & Decrease & 4 & 20 \\
\hline Positive & 3 & 15 & Increase & 3 & 15 \\
\hline Negative & 12 & 60 & Change $^{\text {a) }}$ of E-cadherin/cytoplasmatic & & \\
\hline Unknown & 5 & 25 & expression & & \\
\hline yp $\mathrm{Pn}$ & & & Unchanged & 12 & 60 \\
\hline Positive & 1 & 5 & Decrease & 7 & 35 \\
\hline Negative & 3 & 15 & Increase & 1 & 5 \\
\hline Unknown & 16 & 80 & Change $^{\text {a) }}$ of $\mathrm{N}$-cadherin expression & & \\
\hline yp laminin gamma 2 & & & Unchanged & 17 & 85 \\
\hline No/low expression & 17 & 85 & Change $^{\text {a) }}$ of stroma expression & & \\
\hline High expression & 3 & 15 & Unchanged & 8 & 40 \\
\hline yp alpha smooth muscle actin stroma & & & Decrease & 1 & 5 \\
\hline No/low expression & 11 & 55 & Increase & 1 & 5 \\
\hline High expression & 9 & 45 & Unknown & 10 & 50 \\
\hline yp E-cadherin/membrane-bound & & & Change $^{\text {a) }}$ of inflammation & & \\
\hline No/low expression & 17 & 85 & Unchanged & 5 & 25 \\
\hline High expression & 3 & 15 & Decrease & 3 & 15 \\
\hline yp E-cadherin/cytoplasmatic & & & Increase & 2 & 10 \\
\hline No/low expression & 19 & 95 & Unknown & 10 & 50 \\
\hline High expression & 1 & 5 & Change $^{\text {a) }}$ of invasion front & & \\
\hline yp N-cadherin & & & Unchanged & 7 & 35 \\
\hline No/low expression & 20 & 100 & Decrease & 1 & 5 \\
\hline High expression & 0 & 0 & Increase & 2 & 10 \\
\hline yp stroma & & & Unknown & 10 & 50 \\
\hline
\end{tabular}

a) Comparison of pre-induction chemotherapy vs. post-induction chemotherapy. 


\section{Clinical and Experimental Otorhinolaryngology}

Supplementary Table 4. Subanalysis of patients with three cycles of induction chemotherapy: prognostic factor for no pathological complete remission, tumor recurrence, death, and overall survival $(n=12)$

\begin{tabular}{|c|c|c|c|c|}
\hline Measure $^{\text {a) }}$ & No $\mathrm{pCR}^{\mathrm{b})}$ & Recurrence $^{\text {b) }}$ & Death $^{\text {b) }}$ & 2-Year OS ${ }^{c)}$ \\
\hline Sex (male) & 0.505 & 1.000 & 0.700 & 0.317 \\
\hline Age (<median 56 yr) & 1.000 & 1.000 & 0.505 & $0.022^{*}$ \\
\hline Smoker (yes) & 1.000 & 0.665 & 0.157 & 0.057 \\
\hline Alcohol abuse (yes) & 0.121 & 0.584 & 0.371 & 0.052 \\
\hline BMI (<median 27) & 0.079 & 0.408 & 0.091 & 0.172 \\
\hline Localization (cavity of mouth) & 0.505 & 1.000 & 0.700 & 0.303 \\
\hline cT (T2 vs. T3-4) & 0.588 & 0.679 & 0.310 & 0.894 \\
\hline $\mathrm{cN}(\mathrm{N}+)$ & 0.121 & 0.584 & 0.371 & 0.451 \\
\hline Grading (G3 vs. G1-2) & 1.000 & 0.665 & 1.000 & 0.636 \\
\hline HPV (negative) & 0.588 & 0.408 & 0.091 & 0.079 \\
\hline HPV+ and nonsmoker (no) & 1.000 & 0.584 & 0.371 & 0.007 \\
\hline Laminin gamma 2 (low) & 0.621 & 0.782 & 0.425 & 0.617 \\
\hline Alpha smooth muscle actin stroma (low) & 0.621 & 0.782 & 0.338 & 0.743 \\
\hline Alpha smooth muscle actin in vessels (low) & 0.558 & 0.098 & $0.018^{*}$ & 0.096 \\
\hline CD163 (high) & 0.338 & 0.521 & 0.621 & 0.395 \\
\hline E-cadherin/membrane-bound (low) & $0.046^{*}$ & 0.157 & 0.248 & 0.535 \\
\hline E-cadherin/cytoplasmatic (low) & 0.558 & 0.408 & 0.735 & 0.150 \\
\hline $\mathrm{N}$-cadherin & NA & NA & NA & NA \\
\hline Stroma formation (high) & 0.121 & 0.584 & 0.371 & 0.126 \\
\hline Inflammation (high) & 0.558 & 0.679 & 0.310 & 0.222 \\
\hline Invasion front (high) & 0.505 & $0.005^{*}$ & $0.001^{*}$ & $0.047^{*}$ \\
\hline Change $^{\mathrm{d})}$ laminin gamma 2 (not lower) & 0.296 & 0.140 & 0.070 & NA \\
\hline Change alpha smooth muscle actin stroma (not lower) & 0.558 & 0.679 & 0.735 & 0.217 \\
\hline Change E-cadherin/membrane (not lower) & NA & NA & NA & NA \\
\hline Change E-cadherin/cytoplasmatic (not lower) & NA & NA & NA & NA \\
\hline Change $\mathrm{N}$-cadherin & NA & NA & NA & NA \\
\hline Change stroma formation (not lower) & NA & NA & NA & NA \\
\hline Change inflammation (not lower) & NA & NA & NA & NA \\
\hline Change invasion front (not lower) & NA & NA & NA & NA \\
\hline
\end{tabular}

pCR, pathological complete response; OS, overall survival; BMI, body mass index; HPV, human papilloma virus; NA, not applied.

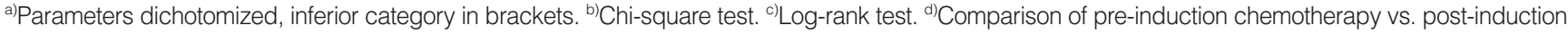
chemotherapy.

${ }^{*} P<0.05$. 
Supplementary Table 5. Influence of baseline tumor parameters on overall survival $(n=20)$

\begin{tabular}{|c|c|c|c|}
\hline Parameter & Dichotomized & 2-Year OS & Log-rank $P$-value \\
\hline All & & 63.5 & \\
\hline \multirow[t]{2}{*}{ Sex } & Male & 64.0 & 0.912 \\
\hline & Female & 60.0 & \\
\hline \multirow[t]{2}{*}{ Smoking } & No & 80.0 & 0.453 \\
\hline & Yes & 58.7 & \\
\hline \multirow[t]{2}{*}{ Alcohol abuse } & No & 85.1 & $<0.001^{*}$ \\
\hline & Yes & 0 & \\
\hline \multirow[t]{2}{*}{ Age (yr) } & <Median 56.0 & 57.1 & 0.618 \\
\hline & $\geq$ Median 56.0 & 70.0 & \\
\hline \multirow[t]{2}{*}{ Body mass index $\left(\mathrm{kg} / \mathrm{m}^{2}\right)$} & $<$ Median 27.0 & 58.3 & 0.419 \\
\hline & $\geq$ Median 27.0 & 68.6 & \\
\hline \multirow[t]{2}{*}{ Localization } & Cavity of mouth & 50.0 & 0.448 \\
\hline & Oropharynx & 72.9 & \\
\hline \multirow[t]{2}{*}{ CT classification } & cT2 & 64.8 & 0.777 \\
\hline & cT3-4 & 62.3 & \\
\hline \multirow[t]{2}{*}{ cN classification } & cNO & 100.0 & 0.317 \\
\hline & $\mathrm{CN}_{+}$ & 60.2 & \\
\hline \multirow[t]{2}{*}{ Therapy arm } & A (1 cycle IC) & 37.5 & 0.102 \\
\hline & B (3 cycles IC) & 81.5 & \\
\hline \multirow[t]{2}{*}{ Tumor reduction first cycle IC } & $<30 \%$ & 16.7 & $0.005^{*}$ \\
\hline & $\geq 30 \%$ & 81.5 & \\
\hline \multirow[t]{2}{*}{ Grading of the pretreatment biopsy } & G1-2 & 61.1 & 0.658 \\
\hline & G3 & 66.7 & \\
\hline \multirow[t]{2}{*}{ Human papilloma virus } & No & 66.7 & 0.852 \\
\hline & Yes & 75.0 & \\
\hline \multirow[t]{2}{*}{$\mathrm{HPV}+$ and nonsmoker } & No & 66.2 & 0.370 \\
\hline & Yes & 100.0 & \\
\hline \multirow[t]{2}{*}{ Laminin gamma 2} & No/low & 66.7 & 0.216 \\
\hline & High & 80.8 & \\
\hline \multirow[t]{2}{*}{ Alpha smooth muscle actin stroma } & No/low & 65.6 & 0.370 \\
\hline & High & 100.0 & \\
\hline \multirow[t]{2}{*}{ Alpha smooth muscle actin in vessels } & No/low & 62.5 & 0.495 \\
\hline & High & 72.7 & \\
\hline \multirow[t]{2}{*}{ CD163 } & No/low & 69.8 & 0.775 \\
\hline & High & 100.0 & \\
\hline \multirow[t]{2}{*}{ E-cadherin/membrane-bound } & No/low & 65.2 & 0.629 \\
\hline & High & 75.0 & \\
\hline \multirow[t]{2}{*}{ E-cadherin/cytoplasmatic } & No/low & 55.9 & 0.348 \\
\hline & High & 85.7 & \\
\hline \multirow[t]{2}{*}{$\mathrm{N}$-cadherin } & No/low & 59.3 & NA \\
\hline & High & - & \\
\hline \multirow[t]{2}{*}{ Stroma formation } & Low & 72.0 & 0.231 \\
\hline & High & 53.3 & \\
\hline \multirow[t]{2}{*}{ Inflammation } & Low & 66.7 & 0.959 \\
\hline & High & 72.7 & \\
\hline \multirow[t]{2}{*}{ Invasion front } & Low & 81.3 & $0.019^{*}$ \\
\hline & High & 33.3 & \\
\hline
\end{tabular}

OS, overall survival; IC, induction chemotherapy; NA, not applied.

${ }^{*} P<0.05$. 